\title{
Digital Communication in Educational Process: Development Trends and New Opportunities
}

\author{
Izabella D. Belonovskaya ${ }^{{ }^{*}}$ \\ (iD) 0000-0003-0968-8764 SC 55576101400 E-6660-2015
}

Elena G. Matvievskaya ${ }^{2}$

(iD) 0000-0003-4182-1297 SC 57202088383 AAB-8474-2020

Elvira R. Saitbaeva ${ }^{3}$

SC 55935211700 AAB-8429-2020

Alla N. Ksenofontova 4

(iD) 0000-0002-7167-2897 SC 57204951211 AAB-8088-2020

Salavat M. Usmanov ${ }^{5}$

(D) 0000-0001-7922-1831 SC 7003691589 J-7292-2017

Mariya B. Zatsepina ${ }^{6}$

(iD) $0000-0002-8133-8614$ SC 57195977071

Elena V. Bakshaeva 7

${ }^{1}$ Department of Technology of Mechanical Engineering, Metalworking Machines and Complexes, Orenburg State University, Orenburg, RUSSIA

2 Department of Preschool, Correctional, Additional Education and Problems of Education, Orenburg State Pedagogical University, Orenburg, RUSSIA

${ }^{3}$ Department of Education Management Orenburg State Pedagogical University, Orenburg, RUSSIA

${ }^{4}$ Department of Pedagogy of Higher Education, Orenburg State Pedagogical University, Orenburg, RUSSIA

${ }^{5}$ Department of Higher Mathematics and Physics, Birsk Branch of Bashkir State University, Birsk, RUSSIA

${ }^{6}$ Department of Aesthetic Education of Preschool Children, Moscow Pedagogical State University, Moscow, RUSSIA

7 Department of Theory, History, Methods of Music and Choral Conducting, I. Yakovlev Chuvash State Pedagogical University, Cheboksary, RUSSIA

${ }^{*}$ Corresponding author: t251589@mail.ru

Citation: Belonovskaya, I. D., Matvievskaya, E. G., Saitbaeva, E. R., Ksenofontova, A. N., Usmanov, S. M., Zatsepina, M. B., \& Bakshaeva, E. V. (2020). Digital Communication in Educational Process: Development Trends and New Opportunities. Online Journal of Communication and Media Technologies, 10(2), e202008. https://doi.org/10.29333/ojcmt/7928

\section{ARTICLE INFO}

Received: 10 Dec 2019

Accepted: 11 Mar 2020

\section{ABSTRACT}

The relevance of this article is in the need to study digital communications that affect the quality and content of education, its compliance with modern requirements and determine the level of intellectual potential of society. The University, as a Communicator, an intermediary between the student and the information provided to it, is forced to change the centuries-old traditions in order to stay on the market, in the face of fierce competition of the appeared open distance courses. The purpose of the research is to analyze the role of digital communication in the educational request of students. Research methods: As research methods, the following one was used: online questionnaire survey that allows you to analyze the prerequisites for the development of digital communication in the educational process and identify new opportunities in education through the personal account of the student. Research results: the article examines the reasons for using the personal account and determines the prospects for its further development in the University environment. The satisfaction of using a personal account from mobile devices among active users-students was studied. The existing problems

Copyright ( $\odot \mathbf{2 0 2 0}$ by authors; licensee OJCMT. This article is an open access article distributed under the terms and conditions of the Creative Commons Attribution License (http://creativecommons.org/licenses/by/4.0/). 
are identified and the reasons for the rare use of the personal account are identified, strategies for attracting students' attention to the personal account are formulated. The novelty and originality of the research lies in the fact that the concept of digital communication is considered in the context of education and its functions are highlighted. The main features of digital communication are presented. The level of approval of existing and potential innovations by active student users (chat for communication, modified portfolio, task scheduler and Bulletin Board from the Institute) is determined. The opinion of students regarding the content of the main page of the personal account is revealed. The preconditions for the development of digital communication in the educational process are investigated: the emergence of digital natives' generation; the resulting request to continuing education; growing importance of self-education; formation of the concept of anticipatory learning; rapid development of open education; a trend to introduce elements of gamification into educational process; the universal gadgetization. The essence of the information and educational environment of the University and the opportunities it provides are studied. The possibilities of the student personal account as a single information space are considered. Recommendations for the modernization of the personal account are given: to rename the group of incomprehensible and non-visited subsections by students; to change the content of the main page by moving the schedule and the number of the school week on it. The research identifies problems with color (the ideal option that would solve a large number of problems, according to students, is the ability to independently design the color scheme or a choice of several options) and the design of the personal account (the main emphasis in the development of the personal account is most effective to make the development of a convenient and visual system of informing students; self-filling the main menu of the personal account, students themselves formulate the need for personalization of the personal account).

Keywords: student youth, digital communication, University, information space

\section{INTRODUCTION}

At all times, researchers have seen problems in the education system that were questioned and criticized, offering new, relative to their time, views on the learning process. The first critical views on the traditional education system appeared in the works of classical teachers, psychologists and sociologists. They sought to describe the essence of education as a social phenomenon, its place in public life and its dependence on the social order. Their work marked the beginning of such a branch of sociology as the sociology of education. In addition, they wrote about the need to transform the traditional model of education (Alisov et al., 2018; Bayanova et al., 2019; Bubnova et al., 2018; Lebon, 2011; Marx, 1949; McLuhan, 2003; Spencer, 2003; Zimmel, 1996). The educational process is based on communication. Communication as a type of active interaction between objects of any nature, involving information exchange. The educational process can only be effective if there is feedback between all parties (Albekov, 2017; Baranov et al., 2019; Cherdymova et al., 2019a, 2019b; Ezhov et al., 2019; Ivanova, 2016; Kosyrev \& Streltsov, 2015; Putilina et al., 2019; Savchuk, 2008). Accordingly, digital communication involves information exchange between communication participants in a digital environment. Means of communication can be understood as various technologies that facilitate people's communication. These various artifacts act as external organs of a person or his external extensions (McLuhan, 2003). In the world, there is a tendency to unite the digital information space of the country's universities into a single platform for communication and exchange of experience, integration into the world information and educational space (Danilchuk, 2002). In the information society, the educational process is increasingly moving to the screens of electronic devices as integral life companions of every modern person.

The development of digital communication in the educational process has a number of prerequisites associated with changing the goals and methods of education in the information society. It is worth noting that continuing education concerns not only modern youth, but also older generations, who will also be affected by new technologies in the very near future. For example, in a University environment, it is necessary to introduce continuing education for teachers in order to maintain their competitiveness in the digital world of education (Baibarin, Mashkin, \& Shelengovskiy, 2016; Chernyavskaya, 2011; Cherdymova et al., 2018; Fedyunin \& Goncharova, 2012; Kargapoltseva et al., 2019; Lugovskaya, 2016 a, 2016b). The basis of professional and personal development of a specialist, according to some scientists is the independence, involving the following components: self-awareness as awareness of their capacities, abilities, aspirations to raise the social status; self-esteem as a positive or negative attitude to their personal qualities; self- 
organization as an independent organization of the learning process, monitoring, evaluation, adjustment of operations; government as the definition of rules of personal actions' organization, in accordance with the values and preferences (Albekov, 2017; Baranova, 2015; Dautova, 2018; Noskov, 2016; Shevko \& Turutina, 2014; Ushakova, 2014).

The ability to independent cognitive activity, acquired in the course of University education, is considered in the information society as a skill necessary throughout life (Stepanova \& Esmurzaeva, 2015). All the abovedescribed social transformations in the field of education associated with digitalization affect the formation of the final educational request of students. An educational request can be understood as, on the one hand, educational needs, and on the other - positive expectations associated with a particular educational institution, targeted educational request or with the field of education in General, objective educational request (Kulikova \& Yakovleva, 2017). The digital information and educational environment can provide the greatest assistance in mastering the skills demanded by modern times in the context of higher education. The educational service of the University in the information society is to provide access to a huge volume of structured multimedia knowledge with easy navigation, showing students a variety of learning perspectives (Lugovskaya, 2016a, 2016b). Thus, the educational services of the University are not only the transfer of knowledge through lecture notes and literature recommended for reading.

\section{MATERIALS AND METHODS}

The basis of the information and educational environment for a student is his/her personal account, a personalized virtual workspace of a student, teacher or University employee in closed access, in which services are provided according to the status and authority of the user. Personalization is the possibility of individual choice of the student regarding the need to receive various kinds of information, allowing you to create an individual comfortable educational environment for students, to which they will want to return and work in it.

The study tested the main functions of the student's personal account: information-based (knowledge base, news, extracurricular information); motivational (gamification, statistics, achievement data); communicative (chat with University staff).

To solve the tasks set in the study, the respondents were divided into two groups: active users of the personal account. It included students who used their personal account once a month and more often. $69 \%$ of such students were identified.

The second group included inactive users of the personal account. They used the office less than once a month. $31 \%$ of such students were identified. They were asked a different list of questions. The first acted as experts in the use of the personal account, evaluated it, identified problems and offered solutions, and the second-as representatives of students who had yet to be interested in using it more often.

The reasons for frequent use of the personal account were found out with the help of the question for what purpose did they usually use the personal account. (With a choice of multiple answers). Only active users of the personal account who used it once a month and more often answered. They made up $69 \%$ of the total number of respondents. It turned out that almost all students used the personal account in order to obtain information. Only $10 \%$ were interested in entering any data about themselves and only $4.5 \%$ considered the personal account as a platform for communication. Based on these data, we can draw the following conclusions: it is necessary to work out in more detail the development of the information unit in the personal account, taking into account the needs of students, focusing on it the main resources. Informing, being the main function of digital communication in education, has only confirmed its importance in practice; it may be worth trying to form new goals for users to visit their personal account. For example, the need to fill out a portfolio can be formed by providing an opportunity for its further use through applying for scholarships and University competitions or sending it to the employer. To the question, are they satisfied with the speed of their personal account -only active users of the personal account answered, $81 \%$ of them were satisfied with its speed. It can be assumed that the dissatisfaction of the remaining 19\% may be partly due to speed problems on their part, for example, the low speed of their Internet or device. In General, you can evaluate the speed of work as good and do not put an increase in speed in the primary tasks of the development of the Cabinet. To the question, is it currently Convenient for them to use the schedule in their personal account- only active users 
of the personal account answered. If we discard the percentage of users who answered that they do not use this section (19\%), it turns out that $62 \%$ of active students are satisfied with the work of the section, and $38 \%$ of users, respectively, are not satisfied. The importance of solving the problem with the schedule is shown by the fact that $81 \%$ of all active users use this section; it is one of the most popular in the student's personal account. Therefore, an assessment of the usability of the schedule is not sufficient.

\section{RESULTS}

To understand what problems students are experiencing with the schedule, let us turn to open questions. In the process of analysis the study highlighted the following areas of the existing problems with the schedule: errors in the schedule: schedule is displayed only for the first two weeks or is absent; the schedule is not always open; incorrect (incomplete) information in the schedule (there is no division into subgroups, causing confusion; there is no indicator for the current week; there are no numbers of classrooms; the data do not coincide with the schedule in the Dean's office or on the website, contrary to them; teachers' names are incorrect in the schedule; there are problems with the display of stream lectures; problems with displaying the timing of lectures; changes to the schedule are not displayed (for example, canceling or rescheduling of the lesson).

Satisfaction with the use of a personal account from mobile devices was revealed by the question was it convenient for them to use a personal account using mobile phone where only active users of the personal account answered. If we discard the percentage of users who enter the personal account only from a personal computer (26.5\%), the convenience of using the personal account from a mobile device was noted by $67 \%$ of students. $33 \%$ of students who were interested in using their personal account from a mobile phone considered it inconvenient to use their personal account from a mobile device. In General, the problem is quite significant, since $74 \%$ of active users prefer a mobile phone, but less significant than the problems with the schedule. To understand what problems students have with displaying their personal account on a mobile device, let us turn to the open questions. The following areas of existing problems with the work of the personal account in a mobile device are highlighted: errors (a warning about the page's insecurity is displayed; the phone does not always open, sometimes loads a white background; some pages do not open or are not presented at all; information from sections periodically disappears; does not go through the Personal account button; slow page loading speed); interface (the schedule in the personal account from the phone is very unreadable; elements spread across the screen and beyond, the text moves; periodically produces a very large or small font; the design of the buttons is not easy to click (small); the menu tab is not closed by scrolling).

Thus, the correction of even some of the identified problems will significantly increase the usability of the schedule in the personal account.

To the question, whether they use authorization in their personal account through third-party services, in addition to the existing authorization the following can be said: in accordance with the wishes of the developers, active users were presented with three options for authorization (with the possibility of selecting several options). This authorization is through the search engines Google, Yandex and social network Vkontakte. It is known that the number of students in the social network "Vkontakte" tends to $100 \%$, and it thus unites them (hence the lack of interest in the chat inside the personal account). Therefore, authorization via the Vkontakte network is desirable. The other options did not pass the threshold of satisfaction with authorization (39\%), although the Google search engine seems to be a good addition (35\%). The lack of authorization through Yandex will not bring much inconvenience to students - it was chosen by only $12 \%$.

To the question why do they use their personal account so rarely (with the possibility of choosing several options for the answer), only inactive users of the personal account who used it less than once a month answered. They make up $31 \%$ of the total number of respondents. It turned out that the main reason why students did not use (or very rarely used) a personal account was the lack of need for it among the respondents. It is interesting that this formulation was not initially included in the list of options for answers and was formulated already during the piloting of the questionnaire, from the open responses of respondents. Subsequently, it became the leader (51\%). The second place is occupied by the reason for the lack of information (43\%), which is combined with the demand for information among active people. 
Informing students about updating their personal account. The results of the study show that $64 \%$ of all respondents are aware of the changes. The question did they know that their personal account was updated was given solely for informing and, at least, $36 \%$ of the respondents learned about the changes in their personal account. It is also possible that the survey participants will continue to monitor the changes taking into account their wishes, which they indicated in the questionnaire. The request - to rate the design of the new personal account - was given to all participants of the survey. The overall rating of the design was quite favorable, $53 \%$ of students rated it as rather attractive and another $12 \%$ as very attractive. At the same time, only $14 \%$ gave a negative assessment. At the end of the study, we can divide all the topics in the menu on the categories: understandable (these include: schedule, current performance, interim certification, news, portfolio, work plan, books on hand, search for literature, scientific publications) - were chosen by $70 \%$, as which are obvious by the contents; obscure (these include: Wi-Fi, bookshelf, manuals, reference-help) were chosen by 50\%; not clear (these include: recommended, patents, approval, expert opinions), were chosen by less than $50 \%$. This category should be renamed, made more understandable for student comprehension, because this is their personal account, not the University staff's.

\section{DISCUSSIONS}

The advantage of the personal account is, first, the possibility of convenient structuring and categorization of information, which is not available in other channels of information. Secondly, all the necessary information for the student is in one place with easy navigation through the personal account. Third, the information in the personal account is personalized for the student.

Fourth, part of the information in the personal account for the student is unique; it is not in the General sources of information (for example, student performance). These advantages should be emphasized when adjusting personal account: one need to work to increase the volume of useful and relevant information in the personal account. To do this, first, we need to prepare a convenient platform for newsletters, make it personalized, and secondly, conduct training work with deans and departments of faculties, so that they can independently upload news ads to their personal account; correcting technical errors and adjusting the interface should be second in priority, after the modernization of the information platform.

The ideal option that would allow solving a large number of problems, according to students, is the possibility of self-designing the color scheme (or a choice of several options) and self-filling the main menu of the personal account, that is, students themselves formulate the need for personalization of the personal account. If students are offered a choice of other sections that are not presented in the menu, then they show a high interest in some of them. From this, we can conclude that students' expectations regarding the personal account are not high, they do not think much about the opportunities that it can provide, but they support them if they talk about them. There is only a predisposition to innovation, which students need to cultivate. Of course, the University's website provides news, but it concerns the entire University, and students want to see news about events, scholarships, events, etc., which are focused on them personally. In open responses, among those who are not satisfied with the representation of existing sections, one can identify the following suggestions for innovations: section with information about teachers: full name, contacts, schedule of their classes. Additional research by the focus group method has shown that contacts and data about teachers are one of the most important information for a student. Students as an important information denote: information about the academic and extracurricular activities of the University; information on recruitment of volunteers for the event; schedule of work of departments - cafes, bars, rectorate, Dean's office, etc.; map of the University, the campuses, with the location of significant sites and objects designated for printing, food, toilets, etc.); information on classes - title, bibliography, notes, materials for download (or links to them); distance learning; jobs for students; information on additional opportunities for student trips, discounts, benefits, etc.; information about research projects that one can join; communication with the Dean's office, and analogies with the support service. 


\section{CONCLUSION}

The main educational request of students in digital communication is aimed at comprehensive information broadcasting about all aspects of academic and extracurricular activities at the University. At the same time, students are no longer satisfied with mass informing everyone about everything, they want to receive personalized information in a structured and visual form, in accordance with their needs. In addition, in the student environment, there is a request for feedback and the need to manage their digital personal information and educational space independently. In General, students do not have a clear educational request or cannot formulate it. However, if you offer them specific solutions to improve the situation, they show a high personal interest in them. Although there may be another reason for this behavior, students simply do not expect serious positive changes in the system of higher education, and therefore they want to distance themselves from existing problems and not think about them. In any case, changes in the information and communication environment of the University will not go unnoticed and will be positively perceived by students, which will lead to an increase in the efficiency of the University.

Special attention should be paid to the mini-organizer, which has the function of self-organization of the student's academic work. This section on the main page should not be mandatory and disabled in the settings, as some students have their own well-established self-organization systems, and in this case, this section will become unnecessary information that attracts attention. However, in the conducted online survey, students noted that they would use such a function, so this possibility of self-monitoring in the personal account should be on the main page, as a recommendation.

Most students want to see the schedule on the main page of their personal account. However, the area of the main page is limited and the introduction of a whole schedule will lead to the displacement of other useful information for students. Therefore, the best option we see is to display the main page of the schedule for the current day. This will allow students to quickly check with their daily routine, without additional page loading and unnecessary transitions, which is especially convenient in case of haste.

Thus, even partial implementation of the indicated sub-items will make the personal account more comfortable for the student. Some of them can be combined. The problem here is that for some areas of information, it is obviously necessary to connect additional structures to the intensive work in the personal account (for example, the center for public relations or deaneries), but the concentration of useful information to the student in one place can give a very good result for student activity.

\section{REFERENCES}

Albekov, A. U. (2017) University educational media environment designing. Media education, 2, 86-95.

Alisov, E. A., Cherdymova, E. I., Trubina, G. F., Yakushev, A. N., Zhdanov, S. P., Popova, O. V., Kobzar-Frolova, M. N. (2018). Study of Dominant Type of Student Ecological Focus. Ekoloji, 27(106), 357-362.

Baibarin, A. A., Mashkin, N. A., \& Shelengovskiy, P. G. (2016). The Northwest Caucasus from Ancient Times to the 19th Century: A Historiographical Review of the Recent Publications in the Periodicals. Rusin, 46(4), 119-140. https://doi.org/10.17223/18572685/46/8

Baranov, V. V., Cherdymova, E. I., Novikov, S. B., Lukina, E. V., Kazurov, O. A., Korzhanova, A. A., \& Gurbanov, R. A. (2019). Student attitude to ethical consumption as new ecological practice. Humanities \& Social Sciences Reviews, 7(4), 1173-1179. https://doi.org/10.18510/hssr.2019.74160

Baranova, I. D. (2015). Modern information and educational environment of University as mechanism for implementing requirements of new generation standards. News of Russian state pedagogical University named after A. I. Herzen, 177, 70-73.

Bayanova A. R., Vodenko K. V., Sizova Zh. M., Chistyakov A. A., Prokopiev A. I., \& Vasbieva D. G. (2019). A Philosophical view of organizational culture policy in contemporary universities. European Journal of Science and Theology, 15(3), 121-131.

Bubnova, I. S., Khvatova, M. A., Chernik, V. E., Popova, O. V., Prokopyev, A. I., Naumov, P. Yu. \& Babarykin, O. V. (2018). Research of Professional Activity Features of Ecologist at Carrying Out Public Ecological Examination. Ekoloji, 27(106), 999-1006. 
Cherdymova, E. I., Ilkevich, T. G., Spirina, E. V., Blinov, L. V., Aliyev, H. K., Kukhtyaeva, E. A., \& Ivanshina, I. A. (2019a). Physicality Ecology: Student Attitude to Their Own Body. Ekoloji, 28(107), 4925-4930. Article No: e107557.

Cherdymova, E. I., Prokopyev, A. I., Karpenkova, Y. V., Pravkin, S. A., Ponomareva, N. S., Kanyaeva, O. M., Ryazapova, L. Z. \& Anufriev, A. F. (2019b). EcoArt Therapy as a Factor of Students' Environmental Consciousness Development. Ekoloji, 28(107), 687-693.

Cherdymova, E. I., Vorobyeva, K. I., Romashkova, O. V., Mashkin, N. A., Grigoriev, S. M., Romanchenko, L. N., Karpenko, M. A. and Bayanova, A. R. (2018). Photo Exhibition Influence on Student Environmental Consciousness Formation. Ekoloji, 27(106), 1271-1278.

Chernyavskaya, A. L. (2011). Learning Theory in information society. Problems of modern education, 4, 87-91.

Danilchuk, E. V. (2002). Modernization of education in information society and teacher information culture. News of Russian state pedagogical University, 4, 153-161.

Dautova, O. B. (2018). Educational communication: traditional and innovative technologies. Teacher book for General education teachers. Schools. St. Petersburg.: "CARO". 172 p.

Ezhov, K. S., Cherdymova, E. I., Prokopyev, A. I., Fabrikov, M. S., Dorokhov, N. I., Serebrennikova, Yu. V., Belousov, A. L., \& Efimova, O. S. (2019). Conflict Features Depending on Stay Duration at Workplace. Dilemas contemporáneos: Educación, Política y Valores, VI, Special Edition, p. 38.

Fedyunin, D. V., \& Goncharova, N. Yu. (2012). Modern features of digital communications building and their effectiveness [Electronic resource] CFIN.RU: Corporate management website. Retrieved on 27 December 2019 from https://www.cfm.ru/press/practical/2012-II/05.shtml

Ivanova, K. L. (2016). Independent work of students in conditions of information and training environment. International information and analytical magazine. Crede Experto: transport, society, education, language, 3, 1-9.

Kargapoltseva, N. A., Rakhimova, O. N., Shabalina, L. G., Guryanova, T. Y., Mashkin, N. A., Mirzalimov, R. M., \& Popova, N. F. (2019). Student Identity and Various Procedures of its Development. International Journal of Applied Exercise Physiology, 2(1), 519-526.

Kosyrev, V. P., \& Streltsov, V. V. (2015). Formation of information educational environment of University. Bulletin of Moscow state University of culture and arts, 2, 214-218.

Kulikova, S. S., \& Yakovleva, O. V. (2017). Educational inquiry of students in the conditions of information environment development. News of Voronezh state pedagogical University, 9, 22-27.

Lebon, G. (2011). Psychology of peoples and masses. Moscow: Academic project publishing house. 238 p.

Lugovskaya, M. V. (2016a). Improvement of educational services based on corporate knowledge management. Discussion, 7, 80-85.

Lugovskaya, M. V. (2016b). Corporate knowledge in the practice of University management. Development of modern science: theoretical and applied aspects, 1, 58-59.

Marx, K. (1949). Capital: Critique of political economy. Moscow: Gospolitizdat publishing house. 794 p.

McLuhan, M. (2003). Gutenberg's Galaxy: Creation of human being of print culture. Moscow: Nika-Center publishing house. $432 \mathrm{p}$.

Noskov, M. V. (2016). Informatization of education in higher education: current $\mathrm{fA}$ issues of electronic libraries development. Bulletin of TSPU, 1(166), 151-155.

Putilina, E. S., Cherdymova, E. I., Kurbanov, R. A., Belyalova, A. M., Shatskaya, I. I., Kobzeva, E. I., Zhuravleva, M. V., \& Meleshko, G. S. (2019). Ecological relationships in real and virtual environments: contact points. EurAsian Journal of BioSciences Eurasia J Biosci, 13, 1475-1480.

Savchuk, S. (2008). Media Philosophy: formation of discipline. St. Petersburg: St. Petersburg philosophical society.

Shevko, N. R., \& Turutina, E. E. (2014). Electronic educational resources as a tool for educational space formation. In: Scientific notes of Kazan state Academy of veterinary medicine named after N. E. Bauman, 2, pp. 324-329.

Spencer, G. (2003). Upbringing: mental, moral and physical. Moscow: Publishing House of University of Russian Academy of Education. 288 p.

Stepanova, T. Yu., \& Esmurzaeva, Zh. B. (2015). Electronic educational resource as a means of increasing of student cognitive activity. Omsk scientific Bulletin, 5, 86-88. 
Ushakova, O. B. (2014). User's personal account instead of electronic form: first steps to flexible service management. Materials of the all-Russian scientific and practical conference "Electronic resources and technologies of libraries: modern solutions, innovations, opportunities". Krasnoyarsk, pp. 131-137.

Zimmel, G. (1996). Selected. Moscow: Yurist publishing house. 671 p.

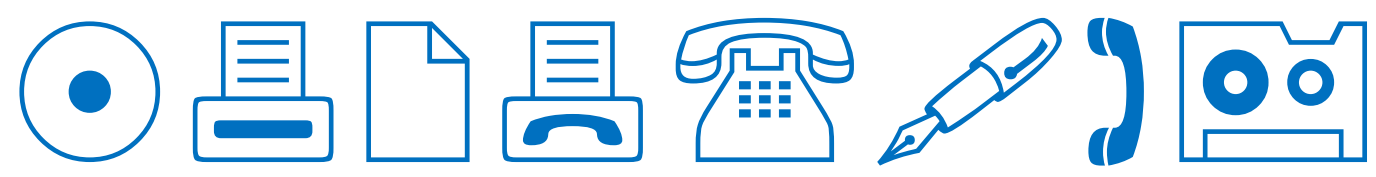

